\title{
Seroepidemiological study of toxoplasmosis in women referred to a pre-marriage counseling center in Alborz Province, Iran
}

\author{
Melica Shahighi ${ }^{1}$, Aliehsan Heidari ${ }^{*}$, Hossein Keshavarz ${ }^{2}$, Amir Bairami ${ }^{1}$, Saeedeh Shojaee ${ }^{2}$, Monireh Sezavar $^{3}$, \\ Mahboobeh Salimi ${ }^{1}$ and Aref Teimouri ${ }^{4}$
}

\begin{abstract}
Objectives: The aim of the current study was to assess prevalence of Toxoplasma infection and its associated risk factors in women of childbearing-age in central Iran.

Results: Of 400 serum samples assessed for anti-T. gondii antibodies, 81 (20.25\%) samples were positive for anti-T. gondii antibodies, including 74 positive samples (91.3\%) for anti-T. gondii lgG and seven positive samples (8.7\%) for lgG and IgM. Of seven IgG and IgM positive samples, five and two samples were high and low in lgG avidity, respectively. Based on PCR analysis, Toxoplasma infection was detected in one sample with anti-T. gondii lgM and low IgG avidity. The Chi-square test showed significant correlations of T. gondii seropositivity with history of undercooked meat consumption and contacts with cats $(p<0.05)$. In the present study, $79.75 \%$ of the participants were negative for $\lg G$ against T. gondii infection. Furthermore, recently acquired Toxoplasma infection was found using IgG avidity and PCR assays among women of childbearing-age in the study area, which would increase the risk of their fetus becoming infected. Educational program and antenatal screening of childbearing-age women for T. gondii infection may be important primary prevention strategies and help reduce the risk of congenital toxoplasmosis in this population.
\end{abstract}

Keywords: Toxoplasmosis, Women, IgG avidity, ELISA, PCR, Iran

\section{Introduction}

Toxoplasma gondii (T. gondii) is an obligate intracellular protozoan that can infect warm-blooded vertebrates such as mammals and birds. In the life-cycle of T. gondii, domestic cats and felids as a definitive host harboring the sexual parasitic cycle and spreading oocysts through feces. They can infect a wide range of intermediate hosts including humans, birds, and other mammals, when ingested with food or water [1-3]. Detection of Toxoplasma immunoglobulin M (Toxo IgM) is the most common method used to assess the acute infection

\footnotetext{
*Correspondence: aliehsan2001@yahoo.com

${ }^{1}$ Department of Medical Parasitology, School of Medicine, Alborz

University of Medical Sciences, Karaj, Iran

Full list of author information is available at the end of the article
}

during pregnancy [4]. Toxo IgM usually reach detectable levels in the blood, nearly one week after the infection. However, discrimination between past and recent infections is a big challenge because Toxo IgM can persist for several months or years following the primary infection. Hence, diagnosis of acute Toxoplasma infections is not based on the measurement of IgM levels solely [4]. Recently, IgG avidity test is used to differentiate between acute and chronic infection. Avidity is known as the aggregate potency that a combination of polyclonal IgG antibody molecules bonds to antigen. The more duration of infection occurs, the stronger bonds are considerable [4-6]. In Iran, the overall prevalence of toxoplasmosis is $18-68 \%$ in various age groups of various regions of the country [7]. Primary infections in pregnant mothers can lead to protozoan transmission to the fetus, which

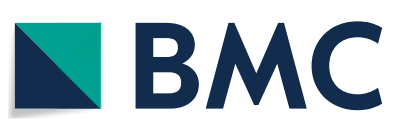

(c) The Author(s) 2021. This article is licensed under a Creative Commons Attribution 4.0 International License, which permits use, sharing, adaptation, distribution and reproduction in any medium or format, as long as you give appropriate credit to the original author(s) and the source, provide a link to the Creative Commons licence, and indicate if changes were made. The images or other third party material in this article are included in the article's Creative Commons licence, unless indicated otherwise in a credit line to the material. If material is not included in the article's Creative Commons licence and your intended use is not permitted by statutory regulation or exceeds the permitted use, you will need to obtain permission directly from the copyright holder. To view a copy of this licence, visit http://creativeco mmons.org/licenses/by/4.0/. The Creative Commons Public Domain Dedication waiver (http://creativecommons.org/publicdomain/ zero/1.0/) applies to the data made available in this article, unless otherwise stated in a credit line to the data. 
results in increased risks of spontaneous abortions, severe congenital malformations and various disorders such as hydrocephaly and microcephaly [8-10]. Awareness of the T. gondii infection statuses in women referred to pre-marriage counseling centers can be an important indicator for estimating number of women at risk of toxoplasmosis during pregnancy [11]. Furthermore, this can help develop appropriate preventive methods such as education in premarital hygiene by identifying susceptible women to $T$. gondii infection and thus prevent congenital toxoplasmosis. In Iran and several countries (except France and Austria) pre-pregnancy tests for toxoplasmosis are not routinely carried out [12]. Based on several studies, seroprevalence of $T$. gondii infection varies widely from 4.6 to $97.2 \%$ in childbearing-age women in various regions of Iran [13]. Although a study has been carried out on the seroprevalence of toxoplasmosis in pregnant women in Karaj City, Alborz Province [14], no studies have been carried out to assess the seroprevalence of the infection in women of reproductive age in this region. Primary infections in pregnant women poses the highest risk for fetal infections. Therefore, this crosssectional study was carried out to assess $T$. gondii infection and its associated risk factors in childbearing-age women referring to counseling centers in Alborz Province, Iran.

\section{Main text \\ Methods \\ Study design}

This descriptive-analytic study was a cross-sectional study, carried out in Alborz Province, from January to April 2017. Inclusion criteria for the participation of women included being married for the first time, not being pregnant, having no serious illnesses, being resident of Alborz Province, and willingness to participate in the study. The exclusion criteria included not being an Iranian, traveling to the province, or not being willing to participate in the study. In total, 29 women were excluded from the study (Fig. 1). The sample size was calculated based on the prevalence of toxoplasmosis in the region, using standard statistical formula (http://www. calculator.net/sample-size-calculator.html), given the prevalence rates of T. gondii as 29\% [14], with a margin of error of 0.05 , and a $95 \%$ confidence interval. This resulted in a sample size of 317. To take account of non-response rate the sample size was inflated by $30 \%$ to get a total sample size of 400 .

\section{Serum collection and assessment}

Samples included 400 serum samples from women of childbearing-age aged between 15 to 45 years. A blood sample (up to $3.5 \mathrm{ml}$ ) was collected from each participant

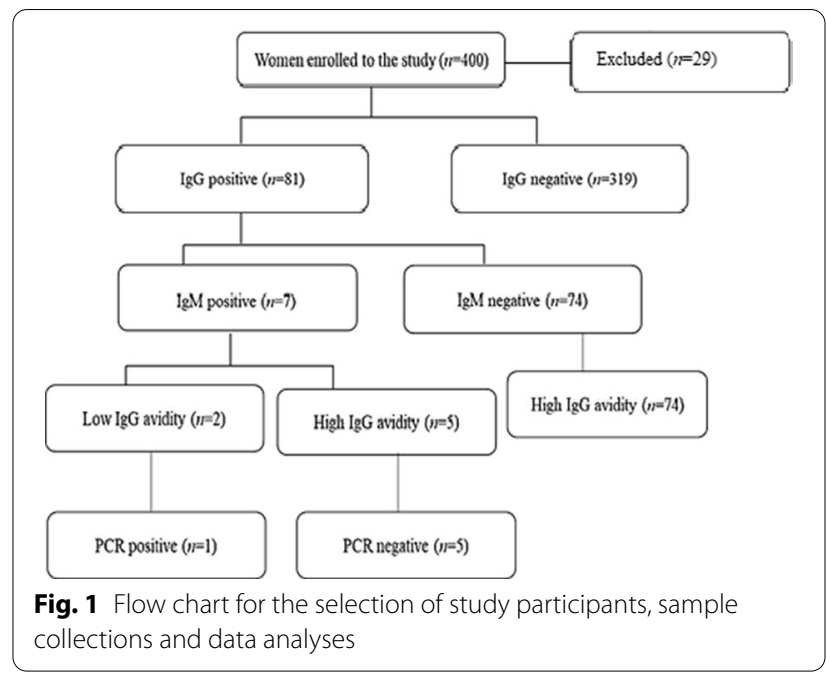

and blood serum was separated and stored at $-20{ }^{\circ} \mathrm{C}$ until use. The anti-Toxoplasma IgG levels of all collected sera were assessed using enzyme-linked immunosorbent assay (ELISA) and the IgG-positive samples were assessed for IgM. The IgG avidity test was carried out on IgG and IgM positive samples. Moreover, all IgM-positive blood samples were further assessed using polymerase chain reaction (PCR) method (Fig. 1). The specific assays used to test for IgG, IgM, IgG avidity, and PCR will be further explained below.

\section{Risk factors}

Through questionnaire survey of the participants, information was collected to assess risk factors at the time of sampling, as previously described [15].

\section{Enzyme-linked immunosorbent assay}

Detection of T. gondii-specific IgM and IgG was carried out using commercial Euroimmun ELISA kits (Euroimmun, Lubeck, Germany) based on the manufacturer's instructions [16].

\section{Immunoglobulin-G avidity test}

Avidity tests were carried out based on the standardized protocols originally described by Hedman et al. using Euroimmun kit according to the manufacturer's instructions [17].

\section{Genome extraction and polymerase chain reaction amplification}

Genomic DNA was extracted from the blood samples with positive anti- $T$. gondii IgM using QIAquick PCR purification kit (Qiagen, Hilden, Germany) based on the manufacturer's instructions. The T. gondii B1 gene was amplified based on a previously described protocol [18]. 


\section{Statistical analysis}

Analytical and descriptive statistics were carried out using IBM SPSS software v.21 (SPSS Inc., Chicago, IL, USA). Associations between the seroprevalence of $T$. gondii and the risk factors were reported using Chisquare test (bivariate test). The $p$-values $<0.05$ were considered statistically significant.

\section{Results}

\section{Distribution of the participants}

The participant average age was approximately 26.8 years $\left(\mathrm{CI}_{95}=24.9-29.7\right)$. Participants were divided into six major age groups of $\leq 18,19-23,24-28,29-33$,

Table 1 Frequency distributions of anti-Toxoplasma gondii lgG in 400 serum samples collected from childbearing-age women in special age groups using ELISA

\begin{tabular}{llll}
\hline Age group (year) & $\begin{array}{l}\text { Positive } \\
\text { serum no. } \\
(\%)\end{array}$ & $\begin{array}{l}\text { Negative } \\
\text { serum no. } \\
(\%)\end{array}$ & $\begin{array}{l}\text { Relative frequencies } \\
\text { within age groups } \\
\text { (\%) }\end{array}$ \\
\hline$\leq 18$ & $1(0.25)$ & $26(6.5)$ & $1 / 27(3.7)$ \\
$19-23$ & $9(2.25)$ & $71(17.8)$ & $9 / 80(11.2)$ \\
$24-28$ & $20(5)$ & $70(17.5)$ & $20 / 90(22.2)$ \\
$29-33$ & $31(7.75)$ & $88(22)$ & $31 / 119(26)$ \\
$34-38$ & $12(3)$ & $47(11.8)$ & $12 / 59(20.3)$ \\
$\geq 39$ & $8(2)$ & $17(4.25)$ & $8 / 25(32)$ \\
Total & $81(20.25)$ & $319(79.75)$ & $81 / 400(20.25)$ \\
\hline
\end{tabular}

34- 38 and $\geq 39$. A largest age group sampled was 29-33 (119/400; 29.75\%).

\section{Seroprevalence of Toxoplasma gondii-specific $\lg G$ and $\lg M$ antibodies}

Of 400 serum samples assessed for anti- $T$. gondii antibodies, 81 samples (20.25\%) were seropositive for anti- $T$. gondii antibodies and 319 samples $(79.75 \%)$ were negative for Toxo IgG. Of the samples seropositive for anti- $T$. gondii antibodies, 74 samples (91.3\%) positive for anti- $T$. gondii IgG and seven samples (8.7\%) positive for IgG and IgM. Of the seven samples positive for anti- $T$. gondii IgM and IgG, five samples were high and two samples were low in IgG avidity assay (Fig. 1). One sample with Toxo IgM and low IgG avidity, analyzed using PCR and showed an expected size of $194 \mathrm{bp}$ band for T. gondii B1 gene that was targeted in the PCR.

\section{Associations of anti-Toxoplasma gondii antibodies with risk factors}

Relative frequencies of anti-T. gondii IgG increased with increasing age (Table 1). As shown in Table 1, the highest relative frequencies within the age groups was seen in $\geq 39$ years of age. Based on the findings presented in Table 2 and Chi-square test, significant associations were seen between the positive cases of T. gondii IgG and age of women $(p=0.008)$. Among the study participants, $1.25 \%(5 / 400)$ had cats in their homes, while $4.25 \%$ (17/400) frequently come in contact with cats because of neighbours owning cats. Chi-square tests showed

Table 2 Bivariate analysis of the risk factors associated with Toxoplasma gondii infection in 400 serum samples collected from childbearing-age women in Alborz Province, Iran

\begin{tabular}{|c|c|c|c|c|}
\hline Variable & Positive serum no. (\%) & Negative serum no. (\%) & $\begin{array}{l}\text { Odds ratio }(95 \% \mathrm{Cl}) \text { (bivariate } \\
\text { analysis) }\end{array}$ & $p$-value \\
\hline \multicolumn{5}{|c|}{ Consumption of raw/undercooked meat } \\
\hline Yes & $9(2.25)$ & $4(1)$ & $9.84(2.94-32.8)$ & $<0.001$ \\
\hline No & $72(18)$ & $315(78.75)$ & & \\
\hline \multicolumn{5}{|l|}{ Contact with cat } \\
\hline Yes & $8(2)$ & $14(3.5)$ & $2.55(1.03-6.34)$ & 0.04 \\
\hline No & $69(17.25)$ & $309(77.25)$ & & \\
\hline \multicolumn{5}{|l|}{ Occupation } \\
\hline Housewife & $49(12.25)$ & $181(45.25)$ & $1.74(0.9-3.21)$ & 0.76 \\
\hline Others $^{a}$ & $32(8)$ & $138(34.5)$ & & \\
\hline \multicolumn{5}{|l|}{ Education level } \\
\hline Illiterate and primary & $13(3.25)$ & $54(13.5)$ & $0.94(0.48-1.82)$ & 0.4 \\
\hline Diploma and university degree & $68(17)$ & $265(66.25)$ & & \\
\hline \multicolumn{5}{|l|}{ Age } \\
\hline$\geq 25$ year-old & $71(17.75)$ & $222(55.5)$ & $3.1(1.53-6.27)$ & 0.008 \\
\hline$<25$ year-old & $10(2.5)$ & & & \\
\hline
\end{tabular}

\footnotetext{
a Students, employees and unemployed individuals. Statistical analysis was carried out using chi-squared analysis. Significance was set at $p<0.05$
} 
significant correlations $(p<0.05)$ between T. gondii seropositivity and histories of undercooked meat consumption and contact with cats (Table 2).

\section{Discussion}

Assessing women's immune statuses against toxoplasmosis before pregnancy can play an important role in preventing the fetus infection during pregnancy. In this study, 81 women $(20.25 \%)$ of 400 women referred to the pre-marriage counseling center were diagnosed as positive for Toxo IgG. Previous studies on women of childbearing-age in various countries have shown prevalence of $58.7 \%$ in Krakow in Poland, $24.4 \%$ in Portugal, $48.3 \%$ in Cameroon, 33\% in Venezuela, $81.4 \%$ in Ethiopia and $35.1 \%$ in Qatar [6, 19-23]. It seems that geographical conditions, dietary habits and spread of cats in each region are linked to differences between the results of this study and those of other studies [6, 14]. Climatic conditions affecting the survival of $T$. gondii oocysts in the environment and, hence, infection rates in meat-producing animals play a major role. Prevalence of $T$. gondii is high in humid tropical countries and conversely, low in arid and colder areas. However, anthropogenic factors explain a large part of the variations in human seroprevalence, including nutritional habits and hygiene practices in meat production [24]. In other studies on women of childbearing-age in Iran, prevalence of IgG anti-T. gondii was reported as $10.6 \%$ in Kerman Province, southern Iran [25] and 74.6\% in Mazandaran Province, northern Iran [26]. Alborz Province is located in the foothills of the Alborz Mountains and has a climate with dry and hot sunny summers and relatively cold winters. Moreover, dietary habits including frequent consumption of undercooked meats, can contribute to the high infection level in Mazandaran Province than in Alborz Province.

In the present study, seven of the 400 total samples (1.75\%) included IgM and IgG against T. gondii, which were lower prevalence, compared to $4 \%$ and $10.7 \%$ of women in childbearing-age with IgG and IgM in central Ethiopia and in the locality of Njinikom, North west of Cameroon, respectively [21, 23]. In Kerman, $2.3 \%$ of women of childbearing-age were positive for IgM against T. gondii [25]. This rate was $1 \%$ in women of this age in Portugal [20] and $1.43 \%$ in India [27], which were further similar to those from the current study. Based on the previous studies, IgM level against $T$. gondii could falsely remain high in blood for months or even years after exposure to the parasite $[28,29]$. Furthermore, natural IgM might react with Toxoplasma antigens in absence of the infection [30, 31]. Therefore, an IgG avidity test was used to further differentiate between individuals with acute and chronic infections $[32,33]$. In the current study, two of the seven sera with anti-T. gondii IgM showed low avidity, indicating possible acute infections. In a study on 128 pregnant women in Morocco, five women were positive for IgM against $T$. gondii, none of which showed low IgG avidity [34]. These findings are similar to findings from the present study and confirm that a positive current $T$. gondii IgM result is not necessarily diagnostic of an acute infection, since IgM can remain positive for several months or years following the primary Toxoplasma infection and false-positive IgM test results can occur. This is in overall agreement with previous reports of persistently positive IgM in chronic toxoplasmosis [28, 31, 35-37]. Therefore, some of the results are doubtful due to difficulty of accurately diagnosing of acute/chronic toxoplasmosis.

Prevalence of $T$. gondii infections in humans varies by age and seroprevalence usually increases with age in most regions, as shown in the current study $[25,27]$. In the current study, significant correlations $(p<0.05)$ were found between the prevalence of $T$. gondii infection and history of exposure to cats and consumption of raw or undercooked meats (Table 2). These findings are similar to those from studies on women of childbearing-age in pre-marriage counseling centers in Kerman and Arak [25, 38]. In a study in Ethiopia, significant correlations were found between exposure to cats and rate of toxoplasmosis [21]. Conversely no correlations were reported in an Indian study between consumption of undercooked meat and toxoplasmosis, possibly because Indians rarely consume raw or undercooked meats [27]. In general, decreases in seroprevalence of T. gondii among women of childbearing-age increase proportions of pregnant women susceptible to primary infections, thus increasing the risk of congenital transmission. In contrast, in societies with high rates of $T$. gondii infection, most women are relatively immune to the infection during pregnancy and help reduce the risk of congenital toxoplasmosis because their previous exposures to the parasite before pregnancy.

\section{Conclusion}

In the present study, 319 out of 400 (79.75\%) serum samples from women were negative for IgG against $T$. gondii; therefore, these women were at risk of acquiring Toxoplasma infection during pre-marriage or pregnancy time. Moreover, recently acquired Toxoplasma infections were found using IgG avidity and PCR assays among women of childbearing-age in the study area, which would increase the risk of their fetus becoming infected. Health education approaches on toxoplasmosis and related risk factors and antenatal screening of childbearing-age women for $T$. gondii infection may be strategies for primary prevention of toxoplasmosis during pregnancy and help reduce the risk of congenital toxoplasmosis. 


\section{Limitations}

In this study, Toxo IgG was assessed using ELISA assay on all collected sera and then, Toxo IgM was assessed on positive samples. Toxo IgM assessment by ELISA in all collected sera was ideal, but was not possible due to financial constraints. This limitation for the study may have impacted the overall T. gondii IgM seroprevalence found in this study. Moreover, another limitation for the study include sampling bias, which only examines women who are about to be married and does not test women who are already married and are planning to have more children.

\section{Abbreviations \\ Toxo IgM: Toxoplasma Immunoglobulin M; Toxo IgG: Toxoplasma Immuno- globulin G; ELISA: Enzyme-linked immunosorbent assay; IBM: International business machinescorporation; SPSS: Statistical package for the social sci- ences; PCR: Polymerase chain reaction; RAI: Relative avidity index.}

\section{Acknowledgements}

All authors would like to thank the Rast Ravesh Health Center staff members for their good cooperation with this study.

\section{Authors' contributions}

MS (Melica Shahighi) and AH conceived, designed and performed the experiments, analyzed and interpreted the data, and wrote the paper. HK, SS, AB, MS (Monireh Sezavar), AT and MS (Mahboobeh Salimi) contributed reagents, materials, analysis tools or data.

\section{Funding}

This study was financially supported by the Alborz University of Medical Sciences, Karaj Iran (Agreement No. 2842898) who provided the necessary resources for the collection of serum samples, ELISA, IgG avidity and PCR studies. The funders had no role in study design, data collection and analysis, publication decision or manuscript preparation.

\section{Availability of data and materials}

All data generated or analyzed during this study are included in this published article. The raw data are available from the corresponding author on reasonable request.

\section{Declarations}

\section{Ethics approval and consent to participate}

The study was carried out based on the principles of the declaration of Helsinki. The current study was approved by the Research Ethical Review Committee of Alborz University of Medical Sciences, Karaj, Iran (approval no. Abzums.Rec1395.26). All participants agreed that their participation was voluntary and were informed that the methodology included no potential risks and that their information was assumed strictly confidential. Informed written consents were signed by all the participants before the study commencement. For the participants under the age of 16 years, parental consents were signed by their parents or guardians.

\section{Consent for publication}

Not applicable.

\section{Competing interests}

The authors declare that we do not have any competing interests.

\section{Author details}

${ }^{1}$ Department of Medical Parasitology, School of Medicine, Alborz University of Medical Sciences, Karaj, Iran. ${ }^{2}$ Department of Medical Parasitology and Mycology, Tehran University of Medical Sciences, Tehran, Iran. ${ }^{3}$ Department of Experimental Sciences, Faculty of Allied Medicine, Alborz University of Medical Sciences, Karaj, Iran. ${ }^{4}$ Department of Parasitology and Mycology, School of Medicine, Shiraz University of Medical Sciences, Shiraz, Iran.

Received: 13 October 2020 Accepted: 22 April 2021

Published online: 30 April 2021

\section{References}

1. Tenter AM, Heckeroth AR, Weiss LM. Toxoplasma gondii: from animals to humans. Int J Parasitol. 2000;30(12-13):1217-58.

2. Lüder CG, Rahman T. Impact of the host on Toxoplasma stage differentiation. Microb Cell. 2017:4(7):203-11.

3. Dubey JP. Toxoplasmosis of animals and humans. 2nd ed. Boca Raton: CRC Press Inc; 2010. p. 1-313.

4. Hill D, Dubey JP. Toxoplasma gondii: transmission, diagnosis and prevention. Clin Microbiol Infect. 2002;8(10):634-40.

5. Liu Q, Wang ZD, Huang SY, Zhu XQ. Diagnosis of toxoplasmosis and typing of Toxoplasma gondii. Parasit Vectors. 2015;8(1):292.

6. Diaz-Suárez O, Estevez J. Seroepidemiology of toxoplasmosis in women of childbearing age from a marginal community of Maracaibo, Venezuela. Rev Inst Med Trop Sao Paulo. 2009;51(1):13-7.

7. Sharbatkhori M, Moghaddam YD, Pagheh AS, et al. Seroprevalence of Toxoplasma gondii infections in pregnant women in Gorgan City, Golestan Province. Northern Iran Iran J Parasitol. 2014;9(1):181-7.

8. Lebech M, Larsen SO, Petersen E. Prevalence, incidence and geographical distribution of Toxoplasma gondii antibodies in pregnant women in Denmark. Scand J Infect Dis. 1993;25(6):751-6.

9. Findal G, Stray-Pedersen B, Holter EK, et al. Persistent low Toxoplasma IgG avidity is common in pregnancy: experience from antenatal testing in Norway. PLoS ONE. 2015;10(12):e0145519.

10. Shojaee S, Teimouri A, Keshavarz H, Azami SJ, Nouri S. The relation of secondary sex ratio and miscarriage history with Toxoplasma gondii infection. BMC Infect Dis. 2018;18(307):1-6.

11. Youssefi MR, Sefidgar AA, Mostafazadeh A, Omran SM. Serologic evaluation of toxoplasmosis in matrimonial women in Babol. Iran Pak J Biol Sci. 2007;10(9):1550-2.

12. Stillwaggon E, Carrier CS, Sautter M, McLeod R. Maternal serologic screening to prevent congenital toxoplasmosis: a decision-analytic economic model. PLoS Negl Trop Dis. 2011;5:e1333. https://doi.org/10.1371/journal. pntd.0001333.

13. Mizani A, Alipour A, Sharif M, et al. Toxoplasmosis seroprevalence in Iranian women and risk factors of the disease: a systematic review and meta-analysis. Trop Med Health. 2017;45:7.

14. Akhlaghi L, Ghasemi A, Hadighi R, Tabatabaie F. Study of seroprevalence and risk factors for Toxoplasma gondii among pregnant women in Karaj township of Alborz Province. J Entomol Zool Stud. 2014;2:217-9.

15. Keshavarz H, Nateghpour M, Zibaei M. Seroepidemiologic survey of toxoplasmosis in Karaj district. Iran J Public Health. 1998;27:8-73.

16. Teimouri A, Modarressi MH, Shojaee S, et al. Detection of Toxoplasma specific immunoglobulin $\mathrm{G}$ in human sera: performance comparison of in house Dot-ELISA with ECLIA and ELISA. Eur J Clin Microbiol Infect Dis. 2018;37(8):1421-9.

17. Hedman K, Lappalainen M, Seppala I, Makela O. Recent primary Toxoplasma infection indicated by a low avidity of specific lgG. J Infect Dis. 1989;159:736-40

18. Burg JL, Grover CM, Pouletty P, Boothroyd JC. Direct and sensitive detection of a pathogenic protozoan, Toxoplasma gondii, by polymerase chain reaction. J Clin Microbiol. 1989;27:1787-92.

19. Abu-Madi MA, Behnke JM, Dabritz HA. Toxoplasma gondii seropositivity and co-infection with TORCH pathogens in high-risk patients from Qatar. Am J Trop Med Hyg. 2010;82(4):626-33.

20. Lopes AP, Dubey JP, Moutinho O, et al. Seroepidemiology of Toxoplasma gondii infection in women from the North of Portugal in their childbearing years. Epidemiol Infect. 2012;140(5):872-7.

21. Gebremedhin EZ, Abebe AH, Tessema TS, et al. Seroepidemiology of Toxoplasma gondii infection in women of child-bearing age in central Ethiopia. BMC Infect Dis. 2013;13(1):101.

22. Salamon D, Bulanda M. Toxoplasma gondii and women of reproductive age: an analysis of data from the Chair of Microbiology, Jagiellonian University Medical College in Krakow. Ann Parasitol. 2014;60(4):291-6. 
23. Wam EC, Sama LF, Ali IM, et al. Seroprevalence of Toxoplasma gondii lgG and IgM antibodies and associated risk factors in women of child-bearing age in Njinikom NW Cameroon. BMC Res Notes. 2016;9(406):1-8.

24. Robert-Gangneux F, Darde ML. Epidemiology of and diagnostic strategies for toxoplasmosis. Clin Microbiol Rev. 2012;25:264-96.

25. Kareshk AT, Keyhani A, Asadi A, et al. Seroprevalence of Toxoplasma gondii infection among childbearing age women in Kerman city, southeastern Iran. J Parasit Dis. 2016;40(4):1544-7.

26. Ajami A, Sharif M, Saffar MJ, et al. Serological study of toxoplasmosis in women referred to Medical Health Laboratory before marriage. Mazandaran J Mazandaran Univ Med Sci. 2000;11(31):51-6 (In Persian)

27. Singh S, Munawwar A, Rao S, et al. Serologic prevalence of Toxoplasma gondii in Indian women of child bearing age and effects of social and environmental factors. Plos Negl Trop Dis. 2014;8(3):e2737.

28. Dhakal R, Gajurel K, Pomares C, et al. Significance of a positive Toxoplasma immunoglobulin M test result in the United States. J Clin Microbiol. 2015;53:3601-5.

29. Villard O, Cimon B, Lollivier C, et al. Serological diagnosis of Toxoplasma gondii infection: recommendations from the French National Reference Center for toxoplasmosis. Diagn Microbiol Infect Dis. 2016;84(1):22-33.

30. Sensini A, Pascoli S, Marchetti D, Castronari R, Marangi M, Sbaraglia G, Cimmino C, Favero A, Castelletto M, Mottola A. IgG avidity in the serodiagnosis of acute Toxoplasma gondii infection: a multicenter study. Clin Microbiol Infect. 1996;2:25-9.

31. Liesenfeld O, Press C, Montoya JG, Gill R, Isaac-Renton JL, Hedman $\mathrm{K}$, Remington JS. False-positive results in immunoglobulin M (IgM) Toxoplasma antibody tests and importance of confirmatory testing: the Platelia Toxo IgM test. J Clin Microbiol. 1997;35:174-8.
32. Teimouri A, Mohtasebi S, Kazemirad E, Keshavarz H. Role of Toxoplasma gondii lgG avidity testing in discriminating between acute and chronic toxoplasmosis in pregnancy. J Clin Microbiol. 2020;58:e00505-20. https:// doi.org/10.1128/JCM.00505-20.

33. Ali-Heidary S, Keshavarz H, Shojaee S, et al. Diagnosis of antigenic markers of acute toxoplasmosis by IgG avidity immunoblotting. Parasite. 2013;20(18):1-4.

34. Laboudi M, Sadak A. Serodiagnosis of toxoplasmosis: the effect of measurement of lgG avidity in pregnant women in Rabat in Morocco. Acta Trop. 2017;172:139-42.

35. Bobic B, Sibalic D, Djurkovic-Djakovic O. High levels of IgM antibodies specific for Toxoplasma gondii in pregnancy 12 years after primary toxoplasma infection. Case report Gynecol Obstet Invest. 1991;31:182-4.

36. Garry DJ, Elimian A, Wiencek V, Baker DA. Commercial laboratory IgM testing for Toxoplasma gondii in pregnancy: a 20-year experience. Infect Dis Obstet Gynecol. 2005;13:151-3.

37. Del Bono V, Canessa A, Bruzzi P, Fiorelli MA, Terragna A. Significance of specific immunoglobulin $M$ in the chronological diagnosis of 38 cases of toxoplasmic lymphadenopathy. J Clin Microbiol. 1989;27:2133-5.

38. Mohammadi A, Shojaee S, Salimi M, et al. Seroepidemiological study of toxoplasmosis in women referred to arak marriage consulting center during 2012-2013. Iran J Public Health. 2015;44(5):654-8.

\section{Publisher's Note}

Springer Nature remains neutral with regard to jurisdictional claims in published maps and institutional affiliations.
Ready to submit your research? Choose BMC and benefit from:

- fast, convenient online submission

- thorough peer review by experienced researchers in your field

- rapid publication on acceptance

- support for research data, including large and complex data types

- gold Open Access which fosters wider collaboration and increased citations

- maximum visibility for your research: over $100 \mathrm{M}$ website views per year

At BMC, research is always in progress.

Learn more biomedcentral.com/submissions 